\title{
Children's body fatness and prevalence of obesity in relation to height for age
}

\author{
Lifoter K. Navti*, Dimple Samani-Radia \& H. David McCarthy
}

Faculty of Life Sciences \& Computing,

London Metropolitan University, Holloway Road, London N7 8DB, UK

$\begin{array}{ll}\text { Correspondence: } & \text { Prof. H. David McCarthy, } \\ & \text { Faulty of Life Sciences \& Computing, } \\ & \text { London Metropolitan University, } \\ & \text { Holloway Road, } \\ & \text { London N7 8DB } \\ & \text { Tel: 020 7133 2547 } \\ & \text { Fax: 020 7133 4062 } \\ \text { email: d.mccarthy@londonmet.ac.uk }\end{array}$

Original article

Running title: Stature and body fatness

Key words: height; children; body fat; BMI, waist circumference

Conflict of interest: HDMc has received prior funding from Tanita UK.

* current address: Catholic University of Cameroon, Bamenda, P.O.Box 782, Bamenda, Cameroon. 
Stature and body fatness

\section{Abstract}

Background: Children who are taller for their age tend to have higher BMI, and as a group, a greater prevalence of overweight/obesity.

Aim: To examine the relationship between height for age with three measures of adiposity.

Subjects and methods: Height, weight, BMI, \% body fat (\%BF) (by bioimpedance) and waist circumference (WC) were measured in 2298 Caucasian children (1251 boys) aged 4.5 to 14 years. Standard deviation scores (SDS) were derived and cases divided into quartiles of height SDS. Mean BMI, \%BF and WC SDSs were compared across quartiles. Prevalence of overweight/obesity, overfat/obesity and abdominal overweight/obesity within each height for age quartile was determined.

Results: Mean BMI, \%BF and WC SDSs increased with increasing quartile of height SDS. Overweight/obesity, overfat/obesity and abdominal overweight/obesity prevalence increased from the first quartile $(8.8-13 \%)$ to the fourth quartile $(32.7-45.5 \%)$ of height SDS. A significant rising trend in mean SDSs for BMI, \% BF and WC was also observed with increasing height SDS in overweight/obese children only.

Conclusion: A higher prevalence of excess weight, measured by BMI SDS among children taller for their age is replicated when using \% BF and WC. Height for age measurement has potential in screening children for later risk of obesity. 
Stature and body fatness

\section{Introduction}

The rising prevalence of childhood obesity is now a global problem (Public Health England, 2013) with the most recent UK findings showing that overweight and obesity now affects almost a third of all children (National Child Measurement Programme, 2011). This is concerning as obesity increases the risk of morbidity in childhood as well risk for type 2 diabetes and cardiovascular disease in adulthood (Juonala et al. 2011). In trying to better understand causation and early risk factors, there is mounting evidence to suggest that some cases of overweight and obesity in childhood could reflect, in part, an altered pattern or rate of growth. Overweight and obese children (identified by their body mass index (BMI) standard deviation score, (SDS)) tend to be taller for their age compared with nonoverweight children (Bosy Westphal et al. 2009, Pliakas and McCarthy 2010). Thus being tall for age could be considered an early predictor for overweight and obesity. For example, rapid weight gain in early infancy has been associated with taller stature at age 3 years, with tallness for age predicting overweight status at that age (Akaboshi et al. 2008). Additionally, an analysis of serial cross-sectional surveys in 3-year-old English children showed the steepest rise in the prevalence of obesity to be amongst the tallest in the study (Buchan et al. 2007). Complimentary studies have shown that taller children tend to have thicker skinfolds compared with their comparatively shorter age group peers (Freedman et al. 2004) and that greater childhood height may be a marker for increased risk of adult overweight and obesity (Stovitz et al. 2010).

Practically all of these population-based studies have used BMI to classify weight status. Although routinely used both clinically and epidemiologically, BMI nevertheless retains several intrinsic limitations. BMI is unable to distinguish between fat mass (FM) and fat-free mass (FFM), it has residual correlation with height in childhood (Hall and Cole, 2006), gives no indication of body fat distribution (McCarthy 2006) and can 
Stature and body fatness

misclassify a sizeable proportion of children with excess body fat as a result of its poor sensitivity (Reilly et al. 2000) - limitations that are accepted but ignored. In contrast to BMI, bioelectrical impedance analysis (BIA), which utilizes the differential conductance properties of fat and lean tissue, provides a more specific and objective assessment of adiposity among children, with sex-specific percentile curves for percentage body fat (\%BF) having now been developed (McCarthy et al. 2006). BIA-derived adiposity measurement avoids this 'hidden' misclassification of children with excess body fat and should able to perform better than BMI in the context of height-adiposity evaluation. Additionally, as an excess abdominal accumulation of body fat carries a higher risk for obesity-related morbidity compared with excess lower body or subcutaneous body fatness, child and youth waist circumference (WC) percentile curves have also been developed to identify those with excess abdominal fat (McCarthy et al. 2001). BMI is unable to identify a high abdominal fat accumulation, especially in those whose BMI may classify them as healthy.

In view of the association between a higher BMI and overweight/obesity prevalence with a greater height for age, the purpose of this study was:

i) to assess whether similar relationships are observed when using BIA to derive a more specific measure of total body fatness, and

ii) to examine the association of being tall for age with abdominal accumulation of body fat and prevalence of abdominal overweight/obesity

Overweight and obese children were then selectively examined to further evaluate total and regional body fat accumulation in relation to height for age. 
Stature and body fatness

\section{Subjects and methods}

\section{Subjects}

This study involved an analysis of cross-sectional data collected between July 2003 and January 2006 from children living in Greater London and neighbouring counties. A total of 2298 Caucasian children (1251 boys and 1047 girls) aged between 4 to 14 years formed the study population. The sample consisted of a mix of socioeconomic groups, including inner city, urban and rural populations but it was not necessarily representative of the UK childhood population. Dates of birth and gender were collected at the same time as the anthropometric measurements. Numbers of children within each age category ranged between 118-196 for boys and 111-156 for girls, with the exception of the 4 year olds (31 boys, 30 girls) 12 year olds (86 boys, 90 girls) and 13 year olds (62 boys, 47 girls). Thus the sample was considered predominantly pre-pubertal.

\section{Anthropometric and body fat measurements}

All measurements were conducted on school premises by trained measurers. Height was measured without shoes (to the nearest $0.1 \mathrm{~cm}$ ) using a Seca height measure. Body weight and $\% \mathrm{BF}$ were measured in light indoor clothing by BIA using the Tanita BC-418MA single frequency $(50 \mathrm{~Hz})$ segmental body composition analyser (Tanita Corporation Tokyo, Japan). The subjects stood with bare feet on the analyser and held a pair of handgrips, one in each hand. Readings of \%BF were produced after approximately 30 seconds per subject. The reliability of this impedance scales used in this study has been indicated in previous studies (McCarthy et al. 2006, Pietrobelli et al. 2004). WC was measured midway between the $10^{\text {th }}$ rib and iliac crest over a shirt, vest or t-shirt by a single trained measurer. The within-observer percentage technical error of measurement was $0.7 \%$ for non-obese and $1.8 \%$ for obese subjects. Due to time constraints during the school day, all measurements were conducted once, children did not undergo overnight fasting prior to the BIA 
Stature and body fatness

measurement and pubertal status was not assessed. BMI was calculated as weight $(\mathrm{kg}) /$ height $\left(\mathrm{m}^{2}\right)$ and FM $(\mathrm{kg})$ and FFM $(\mathrm{kg})$ were obtained from the BIA measurement. Fat-mass Index (FMI) and fat-free mass index (FFMI) were calculated as FM (kg) or FFM $(\mathrm{kg}) /$ height $\left(\mathrm{m}^{2}\right)$. No child was measured where consent had been refused.

\section{Ethical approval}

Ethical clearance was obtained from the Research Ethics Review Panel of the London Metropolitan University.

\section{Statistical analysis}

Children were initially divided into two age groups - 4-9y and 9-14y to generate summary statistics. Data were checked for normality using the Kolmogorov-Smimov (K-S) test. Age, height, weight, $\mathrm{BMI}, \% \mathrm{BF}$ and $\mathrm{WC}$ were summarized by the median and range and anthropometric measures converted to their corresponding SD-scores using the 1990 UK growth reference data (Cole et al. 1995, Freedman et al. 1995), \%BF reference data (McCarthy et al. 2006) and WC reference data (McCarthy et al. 2001). SD-scores were calculated using the LMSGrowth software (Pan and Cole, 2005). The LMS method assumes that the distribution of the measurement, as summarised by the median, coefficient of variation (CV) and degree of skewness, changes smoothly with age (Cole and Green, 1992). SDS-scores were summarized by the mean and standard deviation.

Mean SDSs for anthropometric variables were compared between boys and girls using an independent $t$ test. The International Obesity Task Force (IOTF) overweight BMI cut-off (Cole et al. 2000), the $85^{\text {th }}$ percentile of $\% \mathrm{BF}$ and $91^{\text {st }}$ percentile for WC were used to determine the overall prevalence of children with excess body weight, excess body fat and excess abdominal fat. The rationale for selecting the $85^{\text {th }}$ percentile of $\% \mathrm{BF}$ as the cutoff has been previously described (McCarthy et al, 2006). The $91^{\text {st }}$ percentile for WC was selected as previous studies have demonstrated that the $90^{\text {th }}$ percentile is a suitable 
Stature and body fatness

boundary to define excess abdominal fatness and the $91^{\text {st }}$ percentile appears as a standard curve on UK charts where percentiles are spaced apart at 0.66 SD (Cole et al. 1995, Freeman et al. 2004, McCarthy et al. 2001). Cases were then divided into quartiles of height SDS. A 1-way ANOVA with a post-hoc Bonferroni test was used to compare means of anthropometric variables between quartile groups and the prevalence analysis above was repeated within each quartile of height SDS. The 1-way ANOVA was then extended to a trend analysis using polynomial contrasts to compare mean BMI, \%BF and WC SDS within overweight/overfat/obese children across quartiles of height SDS, with the intention to assess whether overweight/overfat/obese children became comparatively heavier and fatter and with a more abdominal accumulation of body fat for their age, with increasing quartile of height SDS. Statistical procedures were performed using SPSS for Windows version 18. 
Stature and body fatness

\section{Results}

Tables 1 and 2 show the descriptive statistics of the study population by age group and gender. Statistically significant differences were observed between boys and girls in both age groups for height-SDS, weight-SDS and \%BF-SDS ( $P$ ranging between $<0.05$ and $<0.001)$, whereas BMI-SDS and WC-SDS showed no differences.

The prevalence of overweight/obesity (IOTF BMI) and central overweight/obesity WC) was greater in girls than in boys in both age groups whereas prevalence of overfat/obesity was similar between genders in the younger age groups and higher in the boys in the older age group (Table 2).

<Tables 1 and 2 inserted here>

Table 3 shows, by age group, the mean age, height, height SDS, BMI and BMI SDS together with the prevalence of overweight/obesity (IOTF) across quartiles of height SDS. Firstly, mean age across quartiles of height SDS was similar, whereas mean height and mean height SDS (as expected) increased from the first to the fourth quartile. In absolute terms, there was a mean difference in height of $12.9 \mathrm{~cm}$ in the younger group, and $18.7 \mathrm{~cm}$ in the older group, between children in the first (lowest) and fourth (highest) quartile of height SDS, even though mean age was similar. In both age groups, a consistent increase in mean BMI and mean BMI SDS across quartiles of height SDS was observed, indicating that those in the first quartile of height SDS were lightest for their height and those in the fourth were heaviest for their height. When expressed as prevalence, $8.1 \%$ (younger age group) and $11.2 \%$ (older age group) of children in the first height SDS quartile were classified as overweight/obese, rising to $31 \%$ (younger) and $37.3 \%$ (older) of children in the fourth quartile. Of all the overweight/obese children classified by BMI (IOTF) in this sample, $44.6 \%$ (younger) and $41.5 \%$ (older) were found in the fourth quartile of height SDS, with fewer than $12 \%$ (younger) and 13\% (older) in the first quartile of height SDS. 
Stature and body fatness

<Table 3 inserted here>

Table 4 shows the equivalent findings across quartiles of height SDS but based on $\% \mathrm{BF}$ and including FFM and FM. A similar pattern as seen for BMI was observed in both age groups, with children in the first height SDS quartile having the lowest mean FFM, $\mathrm{FM}, \% \mathrm{BF}$ and $\% \mathrm{BF}$ SDS and increasing across quartiles to those in the fourth (highest) quartile having the highest mean values for these variables. The prevalence of overfat/obesity increased from $9.4 \%$ (younger) and $15.0 \%$ (older) among those in the first (lowest) height SDS quartile to $29.7 \%$ (younger) and $33.8 \%$ (older) amongst the children in the fourth (highest) height SDS quartile. In this case, 38\% (younger) and 37\% (older) of all overfat/obese children were categorised in the fourth quartile of height SDS, with $12 \%$ (younger) and 16\% (older) found in the first quartile of height SDS.

$<$ Table 4 inserted here>

Table 5 shows the equivalent findings based on WC. In both age groups, children in the (first) lowest height SDS quartile had the lowest mean WC and mean WC SDS, and those in the fourth (highest) quartile having the highest mean WC and WC SDS. The prevalence of abdominal overweight/obesity was $10.2 \%$ (younger) and $14.5 \%$ (older) in children in the lowest quartile of height for age, increasing to $52.4 \%$ (younger) and $50.9 \%$ (older) of those children in the highest quartile of height for age. $44 \%$ (younger) and $41 \%$ (older) of all abdominally overweight/obese children were categorised within the fourth quartile of height SDS and only 9\% (younger) and 12\% (older) present in the first quartile.

$<$ Table 5 inserted here>

Table 6 shows the mean BMI, \%BF and WC SDSs for the overweight/obese, overfat/obese and abdominally overweight/obese within each quartile of height SDS 
Stature and body fatness

(merged age groups). A significant rising trend was observed for all three measures of adiposity with increasing height SDS quartile at the whole group level (BMI, $\mathrm{p}<0.005$, $\% \mathrm{BF}, \mathrm{p}<0.02, \mathrm{WC}, \mathrm{p}<0.001$ for trends). When boys and girls were analysed separately, the rising trend was significant for BMI $(\mathrm{p}<0.02)$ and $\% \mathrm{BF}$ in boys $(\mathrm{p}<0.03)$ and for $\mathrm{WC}$ in both boys $(\mathrm{p}<0.01)$ and girls $(\mathrm{p}<0.004)$.

$<$ Table 6 inserted here> 
Stature and body fatness

\section{Discussion}

This study set out to further examine the relationship between height for age in children and three measures of excess weight/body fatness and to quantify the prevalence of overweight/overfat/obesity based upon these measures and the equivalent UK reference data in quartiles of height SDS. It confirmed that with increasing quartile of height SDS, mean $\mathrm{BMI}, \% \mathrm{BF}$ and $\mathrm{WC}$ and their respective SDSs also increased, while mean age remained constant. Furthermore, the prevalence of overweight/obesity, overfat/obesity and abdominal overweight/obesity also increased, with the prevalence in the fourth (highest) quartile of height SDS being 3.8 times (BMI), 2.7 times (\%BF), and 4.3 times (WC) higher than that in the lowest quartile. Suggestions for the biological driver(s) underlying these observations, as well as the implications of these findings are warranted.

One earlier assumption had been that this height for age-overweight/obese relationship was, in part, a characteristic of using BMI as the proxy measure for overweight/obesity, with BMI tending to increase with increasing height and that BMI preferentially classified taller children as overweight or obese. However, this height-BMIadiposity phenomenon has been examined in more detail and across different age groups (Akaboshi et al. 2008, Bosy-Westphal et al. 2009, Buchan et al. 2007, Freedman et al. 2004, Pliakas and McCarthy 2010, Stovitz et al. 2010) and has recently been confirmed in a sample of 280 children aged 7-12 years, in whom, body composition was measured using DXA - a laboratory-based reference technique which quantifies tissue masses (Metcalf et al. 2011). The current study, using a simpler field-based method of body composition assessment (BIA), conducted in the community on a larger sample of children and covering a wider age range confirms the findings of the laboratory-based study that children who are taller for their age also tend to have higher body fat levels for their age. The BIA system used in this study and validated against reference methods in healthy children has been 
Stature and body fatness

shown to underestimate body fat mass in obese children (Haroun et al. 2009). As in the development of the body fat references, no correction was made for this underestimation in the obese children in this study although correction should have strengthened the findings. Additionally, this observation extends to a greater accumulation of abdominal fat in children who are taller for their age and greater prevalences of overweight and obesity, overfat and obesity and abdominal overweight and obesity in children who are taller for their age. However, even though the children in this study were ranked by height for age, this does not necessarily imply that enhanced height gain is driving the excess weight and fat gain, but it is equally possible that excess weight and fat gain is driving additional gains in height.

Height at any age point represents accumulated skeletal growth. The linear growth trajectory is highly variable between individuals, with some children displaying comparatively rapid, and others showing relatively slower gains in height, even when the final height achieved may be similar. Childhood (and adult) height is predominantly genetically determined (parental height), with a smaller environmental contribution. According to the ICP (infancy-childhood-puberty) model of growth, the main (non-genetic) factors affecting growth rate (and hence height gain) are diet (infancy), growth hormone(s) (childhood) and sex steroids (puberty). Given the cross-sectional nature of this study and the age range of the children included, it is not possible to define at what time point(s) across childhood a higher height for age may have been achieved and caution must be exercised when considering possibilities. It is interesting to note that the height-adiposity associations were equally observed in the older and younger age groups. The older children who were taller for their age may well have been taller for age when younger and sustained this height differential throughout childhood. Additionally, rapid weight gain in early infancy (driven by diet) has been associated with rapid height gain and taller stature at age 
Stature and body fatness

3 years, which itself predicted overweight status at that age (Akaboshi et al. 2008). Furthermore, infants who display catch-up growth in the first two years of life are heavier, fatter (greater $\mathrm{BMI}, \% \mathrm{BF}$ and $\mathrm{WC}$ ) and taller for their age compared with infants who grow at a slower rate and who do not display catch-up growth (Ong et al. 2000). Importantly, these children were also taller in relation to their parent's height, leading the authors to propose that 'catch-up growth.... may result in acceleration of growth postnatally that overshoots the genetic trajectory' (Ong et al. 2000, p.970). Thus diet and excess weight gain in infancy and childhood either independently or through endocrine actions may promote linear growth beyond the genetic potential of the individual. This suggests that if energy intake is more than sufficient to promote a rapid linear growth, the excess may be stored as fat, resulting in a positive relation between height and adiposity (Freedman et al, 2004). However, caution must again be exercised when attempting to relate height for age (cross-sectional) with growth rates (longitudinal).

Rapid linear growth might also lead to advanced skeletal maturation (evidenced by Fishman's hand-wrist analysis, Demerath et al. 2009), although this observation is not always consistent (Cameron et al. 2003). Advances in skeletal age in overweight or obese individuals appear to precede increases in height, starting in mid-childhood, suggesting that factors involved with physical maturation are aetiologically linked with overweight risk (Johnson et al. 2011). Furthermore, differences in BMI between children following a pathway to overweight/obesity and those on a trajectory to achieving a healthy weight were observed prior to differences in height or skeletal age, therefore supporting the hypothesis that greater relative weight gain in early life is driving faster linear growth and advanced skeletal maturation as opposed to advanced maturation preceding and driving greater size. From an endocrine perspective, both the production and circulating levels of IGF-1 are increased in pre-pubertal obese children and IGF-1 levels are significantly associated with 
Stature and body fatness

increased height SDS and increased bone age in these children (Wabitsch et al 2011). Furthermore, children with increased height SDS have been shown to be more insulin resistant, compared with their shorter for age peers (Metcalf et al. 2011). This insulin resistance could also be driving the greater abdominal fat accumulation identified in this study.

The age range of the children in this study $(5-14 y)$ would indicate that some of the older children, especially the girls, would have commenced puberty. Assessing pubertal status was not possible in this study, yet it is known that both obesity and rapid childhood growth tend to lead to earlier puberty, with earlier puberty ultimately leading to a shorter adult stature (Bosy-Westphal et al. 2009). This may have affected the height-for-age classification in some children, and could have implications for screening older children (see later). Additionally, although an advantage of this study is that only Caucasian children were included in the analysis and so any ethnicity-related differences in height did not introduce bias into the results, this can also be considered a limitation in terms of generalizability of the findings. For this reason, it is important that relationships between height and measures of adiposity also need to be explored in children from other ethnic groups and these analyses are currently being undertaken.

Overweight, overfat, obese and abdominally overweight/obese children were also present (albeit to a lesser extent) in the lower quartiles of height for age. Indeed, 57-59\% of all overweight and obese children were found in the first to third quartiles. These children, despite exhibiting excess adiposity could not necessarily be described as demonstrating enhanced linear growth, although this is dependent, in part, upon their length at birth. The drivers and effects of their excess fat gain/obesity may be different to those children also presenting with greater height for age, and it cannot be concluded that energy intake in excess of needs universally drives greater linear growth. Some of these children may 
Stature and body fatness

require additional investigation, and where a child presents with obesity and short stature for age, referral for specialist investigation is usual.

This study also demonstrated that overweight/obese children who were taller for their age differed in both their level and distribution of body fat for their age compared with overweight/obese children who were shorter for their age. An apparent amplification effect of total, percentage and abdominal distribution of body fat with increasing height for age was observed in boys and girls combined, although this trend was not so strong for $\mathrm{BMI}$ and \% BF when girls were analysed separately. This could be due, in part, to the lower numbers of overweight/over-fat/obese in the sample when stratified by gender. However, when findings are interpreted for boys and girls combined, this could suggest that a greater abdominal accumulation of body fat and greater gains in height are causally linked. A recent study reported that children with a high BMI or WC for their age also had a lower leg length to height ratio compared with children with a lower BMI or WC for age (Pliakas and McCarthy, 2010). This indicated that altered body proportions (trunk and legs) are linked to measures of overweight and obesity in children, with a relatively greater trunk length (which is a corollary of a lower leg length to height ratio) being associated with a greater accumulation of abdominal fat (for age). One could hypothesize that the amplification of abdominal fat accumulation in the taller overweight/obese children compared with the shorter overweight and obese children in this study is driving a proportionately greater trunk growth, but this suggestion requires further investigation.

\section{Conclusion}

In conclusion, this study has demonstrated that being taller for age is associated with having a greater BMI, \%BF and WC for age, with the prevalence of overweight and obesity being highest among the children tallest for their age using these three measures of 
Stature and body fatness

excess weight or adiposity. For this reason, it appears that tallness for age could now be considered a potential early marker for risk for excess weight or fat gain or for developing a more abdominal distribution of body fat. This potential marker most likely would be useful only in prepubertal children. Thus, childhood height could be used to identify more accurately children who may be likely to become overweight or obese in later life - a suggestion that has already been proposed by others, where height measurement could not only improve the identification of obese children but that special attention be paid to children who have a high BMI and are also taller for their age (Stovitz et al. 2008, 2010, Johnson et al. 2011). However, objective monitoring of height among UK children is needed to verify its feasibility and longitudinal studies are also needed to confirm if children with a higher height-for-age could be a group targeted for further assessment. 
Stature and body fatness

\section{Acknowledgements}

The authors gratefully acknowledge Tanita UK, The Learning Trust and the North Central London Research Consortium for funding this research. LN acknowledges the receipt of a London Metropolitan University overseas postgraduate studentship. We thank all the schools and children for participating in this study.

\section{Authorship contributions}

LN undertook the data analysis and drafted the manuscript. DSR undertook the data collection and organisation and contributed to drafting the manuscript. HDMc conceived and coordinated the study, participated in the data collection, undertook data analysis and drafted the manuscript. 
Stature and body fatness

\section{References}

Akaboshi I, Haraguchi Y, Mizumoto Y, Kitano A, Kan H. 2008. Taller stature after postnatal rapid weight gain in early infancy predicts overweight status at age 3. Acta Pediatr 97: 1460-4.

Bosy Westphal A, Plachta-Danielzik S, Doerhoefer RP, Mueller MJ. 2009. Short stature and obesity: positive association in adults but inverse association in children and adolescents $\mathrm{Br} \mathrm{J}$ Nutr 102: 453-61.

Buchan IE, Bundred PE, Kitchiner DJ, Cole TJ. 2007. Body mass index has risen more steeply in tall than in short 3-year olds: serial cross-sectional surveys 1988-2003. Int J Obes Relat Metab Dis 31: 23-9.

Cameron N, Pettifor J, De Wet T, Norris S. 2003. The relationship of rapid weight gain in infancy to obesity and skeletal maturity in childhood. Obesity Res 11: 457-60.

Cole TJ, Bellizzi MC, Flegal KM, Dietz WH. 2000. Establishing a standard definition for child overweight and obesity worldwide: international survey. BMJ 320: 1240-5.

Cole TJ, Freedman JV, Preece MA. 1995. Body mass index reference curves for the UK, 1990. Arch Dis Child 73: 25-9.

Cole TJ, Green PJ. 1992. Smoothing reference centile curves: the LMS method and penalized likelihood. Stat Med 11: 1305-19.

Demerath EW, Jones LL, Hawley NL, Norris SA, Pettifor JM, Duren D, Chumlea WC, Towne B, Cameron N. 2009. Rapid infant weight gain and advanced skeletal maturation in childhood. J Pediatr 155: 355-61.

Freedman DS, Khan LK, Serdula MK, Dietz WH, Srinivasan SR, Berenson GS. 2004. Interrelationships among childhood BMI, childhood height, and adult obesity: the Bogalusa Heart Study. Int J Obes Relat Metab Dis 28: 10-16.

Freedman DS, Thornton JC, Mei Z, Wang J, Dietz WH, Pierson RN, Horlick M. 2004. Height and adiposity in children. Obesity Research 12: 846-52. 
Stature and body fatness

Freeman JV, Cole TJ, Chinn S, Jones PR, White EM, Preece, MA. 1995. Cross sectional stature and weight reference curves for UK, 1990. Arch Dis Child 73: 17-24.

Hall DM, Cole TJ. 2006. What use is the BMI? Arch Dis Child 91: 283-6.

Haroun D, Croker H, Viner RM, Williams JE, Darch TS, Fewtrell MS, Eaton S, Wells JC. 2009. Validation of BIA in obese children and adolescents and re-evaluation in a longitudinal study. Obesity 17: 2245-50.

Johnson W, Stovitz SD, Choh AC, Czerwinski SA, Towne B and Demerath EW. 2011. Patterns of linear growth and skeletal maturation from birth to 18 years of age in overweight young adults. Int J Obesity 36: 535-41.

Juonala M, Magnussen CG, Berenson GS, Venn A, Burns TL, Sabin MA, Srinivasan SR, Daniels SR, Davis PH, Chen W, Sun C, Cheung M, Viikari JS, Dwyer T, Raitakari OT. 2011. Childhood adiposity, adult adiposity, and cardiovascular risk factors. N Engl J Med 365: 187685.

McCarthy HD. 2006. Body fat measurements in children as predictors for the metabolic syndrome: focus on waist circumference. Proc Nutr Soc 65: 385-92.

McCarthy HD, Cole TJ, Fry T, Jebb SA, Prentice, AM. 2006. Body fat reference curves for children. Int J Obes Relat Metab Dis 30: 598-602.

McCarthy, HD, Crawley, HF \& Jarrett, KV. 2001. Development of waist circumference percentiles in British children aged 5.0-16.0 years. Eur J Clin Nutr 55: 902-7.

Metcalf BS, Hosking J, Frémeaux AE, Jeffery AN, Voss LD, Wilkin TJ. 2011. BMI was right all along: taller children really are fatter (implications of making childhood BMI independent of height) EarlyBird 48. Int J Obes Relat Metab Dis 35: 541-7. 
Stature and body fatness

Ong KL, Ahmed ML, Emmett PM, Preece MA, Dunger DB. 2000. Association between postnatal catch-up growth and obesity in childhood: prospective cohort study. BMJ 320: 967-71.

Pan H, Cole TJ. 2005. User's quide to lmsGrowth.

http://shop.healthforallchildren.co.uk/pro.epl?DO=PRODUCT\&WAY=INFO\&ID=185.

Pietrobelli A, Rubiano F, St-Onge MP, Heynsfield SB. 2004. New bioimpedance analysis system: improved phenotyping with whole-body analysis. Eur J Clin Nutr 58: 1479-84.

Pliakas T, McCarthy HD. 2010. Association of leg length with overweight and obesity in children aged 5-15 years: A cross-sectional study. Ann Hum Biol 37: 10-22.

Public Health England 2013. International Prevalence Childhood Obesity revised June 2012 http://www.noo.org.uk/NOO_about_obesity/child_obesity/international

Reilly JJ, Dorosty AR, Emmett PM, ALSPAC Study Team. 2000. Identification of obese children: adequacy of the body mass index for clinical practice and epidemiology. Int $\mathrm{J}$ Obes Relat Metab Dis 24: 1623-27.

Stovitz SD, Hannan PJ, Lytle LA, Demerath EW, Pereira MA, Himes JH. 2010. Child height and the risk of young adult obesity. Am J Prev Med 38: 74-7.

Stovitz SD, Pereira MA, Vazquez G, Lytle LA, Himes JH. 2008. The interaction of childhood height and childhood BMI in the prediction of young adult BMI. Obesity 16: 2336-41.

The Health and Social Care Information Centre, Lifestyles Statistics 2011. National Child Measurement Programme. 2010/11 school year, headline results. Leeds, UK: Health and Social Care Information Centre. Available online at: http://www.hscic.gov.uk/searchcatalogue? productid $=10135 \& \mathrm{q}=$ title $\% 3 \mathrm{a} \% 22$ national+child+measurement+programme $\% 22 \&$ sort=Relevan ce\&size=10\&page=1\#top (accessed November 1, 2013).

Wabitsch M, Reinehr T, Fischer-Posovsky P. 2011. Effect of body weight on endocrine parameters and fat hormones, in Ranke MB (ed.) Diagnostics of endocrine function in children and adolescents, $4^{\text {th }}$ edn. Karger, Basel pp 483-98. 
Stature and body fatness

Table 1.

Summary characteristics by age group and gender

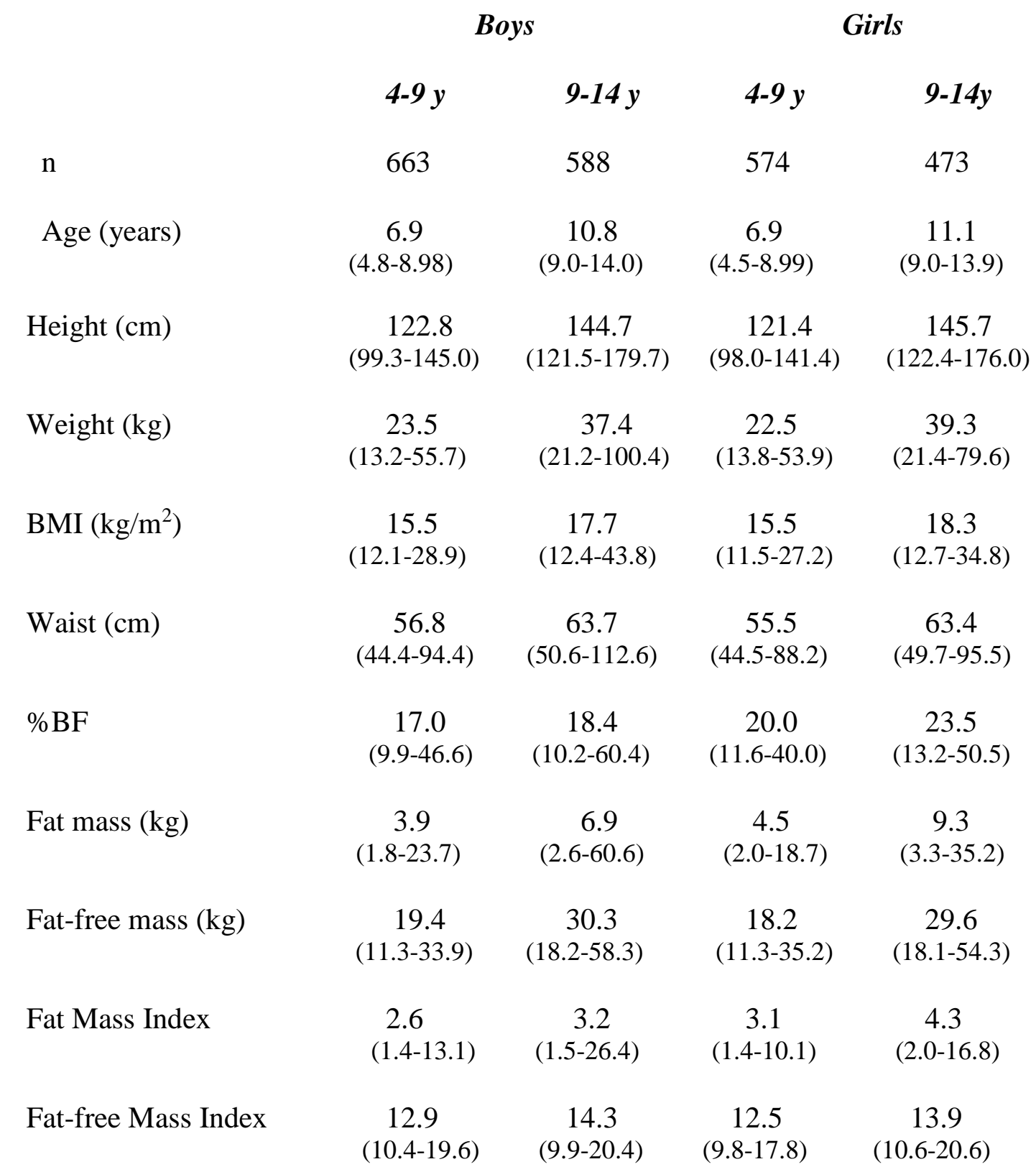

Values $=$ median $(\min -\max )$ 
Stature and body fatness

\section{Table 2.}

Anthropometric standard deviation scores by age group and gender. Values are mean SDS (SD). Prevalence of overweight/obesity

\section{Boys Girls}

\begin{tabular}{|c|c|c|c|c|}
\hline & $4-9 y$ & $9-14 y$ & $4-9 y$ & $9-14 y$ \\
\hline Height-SDS & $\begin{array}{l}0.336 \\
(1.02)\end{array}$ & $\begin{array}{l}0.308 \\
(0.99)\end{array}$ & $\begin{array}{l}0.192 * * \\
(1.02)\end{array}$ & $\begin{array}{l}0.156^{* *} \\
(1.01)\end{array}$ \\
\hline Weight-SDS & $\begin{array}{l}0.224 \\
(1.23)\end{array}$ & $\begin{array}{l}0.444 \\
(1.09)\end{array}$ & $\begin{array}{l}0.095^{*} \\
(1.12)\end{array}$ & $\begin{array}{l}0.308^{*} \\
(1.13)\end{array}$ \\
\hline BMI-SDS & $\begin{array}{l}0.016 \\
(1.28)\end{array}$ & $\begin{array}{l}0.394 \\
(1.19)\end{array}$ & $\begin{array}{l}0.010 \\
(1.14)\end{array}$ & $\begin{array}{l}0.281 \\
(1.21)\end{array}$ \\
\hline Waist-SDS & $\begin{array}{l}0.813 \\
(1.10)\end{array}$ & $\begin{array}{l}0.774 \\
(1.03)\end{array}$ & $\begin{array}{l}0.735 \\
(1.11)\end{array}$ & $\begin{array}{l}0.866 \\
(1.16)\end{array}$ \\
\hline$\%$ BF-SDS & $\begin{array}{l}0.360 \\
(1.07)\end{array}$ & $\begin{array}{l}0.238 \\
(1.08)\end{array}$ & $\begin{array}{l}0.297 * \\
(1.05)\end{array}$ & $\begin{array}{l}0.135^{*} \\
(1.06)\end{array}$ \\
\hline
\end{tabular}

Prevalence (\%)

$\begin{array}{lcccc}\begin{array}{l}\text { Overweight+obesity } \\ \text { (IOTF, BMI) }\end{array} & 15.5 & 20.3 & 19.6 & 24.3 \\ \begin{array}{l}\text { Overfat+obesity } \\ \text { (\%BF) }\end{array} & 21.4 & 24.0 & 24.4 & 21.1 \\ \begin{array}{l}\text { Central } \\ \text { Overweight+obesity }\end{array} & 28.9 & 28.3 & 29.5 & 32.7\end{array}$

Overweight+obesity

(WC)

$* \mathrm{P}<0.05, * * \mathrm{P}<0.001$ vs equivalent age group 
Stature and body fatness

Table 3.

Height and BMI SDS by quartiles of height for age and prevalence of overweight/obesity using the IOTF BMI (25) cut-off.

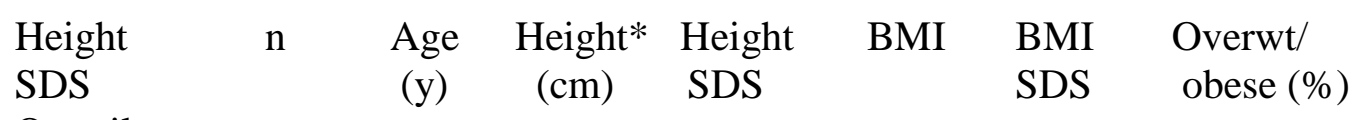

Quartile

4-9y

$\begin{array}{lccccccc}\text { First } & 310 & 6.9 & 115.4 & -0.988 & 14.9 & -0.451 & 8.1 \\ & & (1.1) & (7.1) & (0.55) & (1.7) & (1.1) & \end{array}$

$\begin{array}{llllllll}\text { Second } & 311 & 6.9 & 121.4 & -0.051 & 15.4 & -0.210 & 10.9\end{array}$

$\begin{array}{llll}(1.1) & (6.8) \quad(0.19) \quad(2.2) \quad(1.1)\end{array}$

$\begin{array}{lccccccc}\text { Third } & 310 & 6.9 & 124.0 & 0.585 & 15.7 & 0.153 & 19.0 \\ & & (1.2) & (7.5) & (0.17) & (2.5) & (1.2) & \end{array}$

$\begin{array}{lccccccc}\text { Fourth } & 306 & 6.9 & 128.3 & 1.437 & 16.4 & 0.582 & 31.0 \\ & & (1.2) & (7.8) & (0.44) & (2.9) & (1.3) & \end{array}$

9-14y

$\begin{array}{lccccccc}\text { First } & 267 & 10.9 & 136.0 & -0.981 & 16.6 & -0.141 & 11.2 \\ & & (1.3) & (7.2) & (0.44) & (3.0) & (1.1) & \end{array}$

$\begin{array}{llllllll}\text { Second } & 265 & 11.1 & 143.5 & -0.110 & 17.7 & 0.211 & 15.1\end{array}$

$\begin{array}{llll}(1.3) \quad(7.2) \quad(0.20) \quad \text { (2.9) } & \text { (1.1) }\end{array}$

$\begin{array}{lllllll}\text { Third } \quad 266 & 10.9 & 146.3 & 0.600 & 18.2 & 0.496 & 25.6\end{array}$

$\begin{array}{llllllll}\text { Fourth } & 263 & 11.1 & 154.7 & 1.520 & 19.5 & 0.934 & 37.3\end{array}$

$\begin{array}{lllll}(1.3) & (8.6) \quad(0.48) \quad(3.8)\end{array}$

Values $=$ mean $(\mathrm{SD})$ 
Stature and body fatness

\section{Table 4.}

Fat and fat-free variables by quartiles of height for age and prevalence of overfat/obesity using $85^{\text {th }}$ centile $\%$ BF cut-off

$\begin{array}{llclcccc}\begin{array}{l}\text { Height } \\ \text { SDS }\end{array} & \mathrm{n} & \begin{array}{c}\text { Fat mass } \\ (\mathrm{kg})\end{array} & \begin{array}{l}\text { Fat-free } \\ \text { mass }(\mathrm{kg})\end{array} & \text { FMI } & \text { FFMI } \% \mathrm{BF} & \begin{array}{l}\% \mathrm{BF} \\ \text { Overfat/ }\end{array} & \begin{array}{l}\text { SDS } \\ \text { obese }(\%)\end{array}\end{array}$

\section{4-9y}

First

$310 \quad 3.8$

16.7

(2.7)

$\begin{array}{llll}2.8 & 12.4 & 18.2 & -0.24 \\ (1.0) & (1.0) & (3.7) & (1.0)\end{array}$

9.4

(1.4)

18.7

(2.7)

$\begin{array}{llll}3.0 & 12.7 & 18.6 & -0.11\end{array}$

$(1.0) \quad(1.0) \quad(4.0) \quad(1.1)$

Third

$310 \quad 5.2$

20.3

(3.6)

$\begin{array}{llll}3.3 & 13.0 & 19.6 & 0.14\end{array}$

$(1.5) \quad(1.3) \quad(5.1) \quad(1.2)$

Fourth

306

6.3

22.2

(3.9)

$\begin{array}{llll}3.7 & 13.4 & 21.0 & 0.50\end{array}$

$(1.7) \quad(1.4) \quad(5.6) \quad(1.0)$

\section{9-14y}

(3.3)

25.7

(4.6)

$\begin{array}{llll}3.8 & 13.6 & 21.0 & -0.12\end{array}$

$\begin{array}{llll}(1.8) \quad(1.5) \quad(5.7) \quad(1.0) & \end{array}$

(3.7)

29.6

(4.9)

$\begin{array}{lll}4.0 & 14.2 \quad 21 .\end{array}$

0.10

$(1.8) \quad(1.4) \quad(5.8) \quad(1.1)$

(3.9)

31.7

(5.9)

$\begin{array}{llll}4.4 & 14.5 & 22.2 & 0.25\end{array}$

$(2.0) \quad(1.6) \quad(6.2) \quad(1.1)$

Fourth

$263 \quad 11.9$

37.1

(6.6)

$\begin{array}{llll}5.0 & 15.3 & 23.4 & 0.48\end{array}$

$\begin{array}{llll}(2.6) & \text { (1.7) (6.9) (1.1) }\end{array}$

14.2

24.5

29.7

(6.1)

(6.6)

Values $=$ mean $(\mathrm{SD})$ 
Stature and body fatness

Table 5.

Mean WC $(\mathrm{cm})$ and WC SDS by quartiles of height for age and prevalence of central overweight/obesity using $91^{\text {st }}$ centile WC cut-off.

$\begin{array}{llccc}\text { Height } & \mathrm{n} & \begin{array}{c}\text { WC }(\mathrm{cm}) \\ (\mathrm{sd})\end{array} & \begin{array}{c}\text { WC SDS } \\ \text { SDS }\end{array} & \begin{array}{c}\text { Central overwt/ } \\ \text { obese }(\%)^{*}\end{array}\end{array}$

Quartile

4-9y

First

$310 \quad 54.0$

0.12

10.2

(4.1)

(0.94)

Second

$311 \quad 56.2$

0.58

20.7

(4.6)

(0.93)

Third

$310 \quad 58.5$

(6.5)

1.00

(1.04)

34.4

Fourth

306

60.6

1.44

52.4

9-14y

(6.9)

(1.04)

First

$267 \quad 61.0$

0.22

(1.04)

Second

265

(6.8)

14.5

Third 266
Fourth
Values = mean (SD)
$* \geq 91^{\text {st }}$ centile.

64.1

0.65

(0.98)

22.6

(7.

1.01

(0.95)

(7.8)

1.44

(1.01)

50.9

(9.3)

(1.01)

35.0 


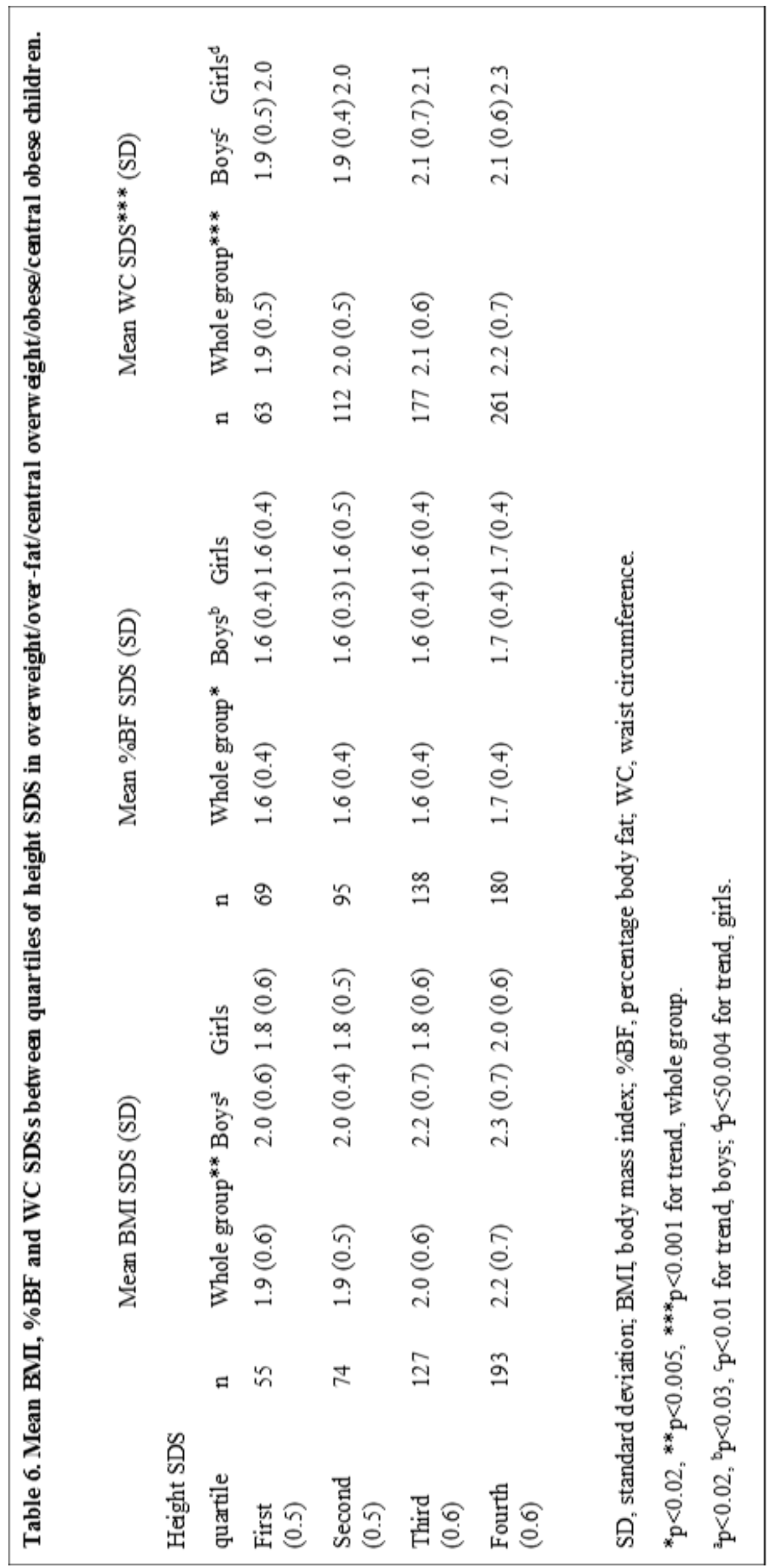

